\title{
The Importance of Prebiotics in Functional Foods and Clinical Practice
}

\author{
Valéria Maria Caselato de Sousa ${ }^{1}$, Elisvânia Freitas dos Santos ${ }^{1}$, Valdemiro Carlos Sgarbieri ${ }^{1}$ \\ ${ }^{1}$ School of Food Engineering, University of Campinas, Campinas, Brazil. \\ E-mail: valcaselato@gmail.com
}

Received November 23 $3^{\text {rd }}, 2010$; revised February $10^{\text {th }}, 2011$; accepted March $1^{\text {st }}, 2011$.

\begin{abstract}
Prebiotics are substances that can promote the growth of beneficial microorganisms, mainly in the intestinal tract, and will modify the colonic microbiota. The following health benefits are attributed to prebiotics: relief from poor digestion of lactose, increased resistance to bacterial infection, better immune response and possible protection against cancer, reduction of the risk of diseases such as intestinal disease, cardiovascular disease, non-insulin dependent diabetes, obesity and osteoporosis. This article presents a discussion of prebiotics, with descriptions of the concepts and its use in clinical practice, and a review of some recent research showing the benefits that these ingredients provide to human health and providing data on the recommended intakes for consumption.
\end{abstract}

Keywords: Prebiotics, Oligossaccharides, Nutrition, Human

\section{Introduction}

The concept of functional foods was introduced in Japan during the 1980s, and it could be defined as "any food or ingredient that may provide a health benefit beyond the traditional functions hitherto known" [1].

Products claiming to be healthier and to have functional and/or health properties have gained prominence in research, in the development of new products and in supermarkets.

Prebiotics can be defined as non-digestible food ingredients that beneficially affect the body by selectively stimulating the growth and/or activity of a limited number of bacteria in the colon [2-7].

To be considered as having prebiotic action, the compound must reach the colon without degradation or alteration and must be a food substrate that stimulates the existing saprophytic bacterial flora. Food ingredients with prebiotic characteristics generally exhibit certain unique characteristics, such as limited hydrolysis and absorption in the upper gastrointestinal tract, selective stimulation of the multiplication of beneficial bacteria in the colon, potential to suppress pathogens and limit virulence by processes such as immunostimulation and the stimulation of the beneficial microflora, which promote resistance to colonization by pathogens [8].

The consumption of prebiotics has been associated with reduced risks of certain diseases. These include the suppression of diarrhea associated with intestinal infections; reduced risk of osteoporosis because inulin promotes the uptake of calcium and thereby increases bone mass; reduced risk of obesity and of developing Type 2 diabetes; neutralization of toxic products and decreased frequency of colon cancer; stimulation of immunity and protection of the urogenital system $[9,10]$.

\section{Prebiotics: Origin and Chemical Nature}

The term prebiotic is applied to substances that promote the growth of beneficial microorganisms in the intestine [11].

Prebiotics are substances that will modify the colonic microflora, stimulating the proliferation and growth of non-pathogenic bacteria with health promoting potential, particularly Lactobacilli and Bifidobacteria [2,6,12]. Some examples of prebiotics include fructooligosaccharides, galactooligosaccharides, arabinose, galactose, inulin, raffinose, mannose, lactulose, stachyose, mannanoligosaccharides, xylooligosaccharides, palatinose, lactosucrose, glycooligosaccharides, isomaltooligosaccharides, soybean oligosaccharides, etc $[4,5,13]$.

The criteria for classifying a food as a prebiotic are:

1) It should not undergo hydrolysis or absorption in the upper gastrointestinal tract;

2) When it reaches the colon, it should be selectively metabolized by a limited number of beneficial bacteria; 
3) It should be able to alter the colonic microflora to a healthier bacterial flora;

4) It should be capable of inducing a physiological effect that is beneficial to health [14].

Prebiotics may exhibit the following properties:

- Maintenance of intestinal flora and stimulation of intestinal transit [15];

- Change in colonic microflora, contributing to normal stool consistency, preventing diarrhea and constipation $[5,16,17]$;

- Elimination of excess substances such as glucose and cholesterol, favoring only the absorption of substances needed [2];

- Stimulation of the growth of bifidobacteria [18];

- Stimulation of the absorption and production of B vitamins (B1, B2, B3, B6, B9, B12) [19];

- Support of the immune system [12];

- Contribution to the control of obesity [14];

- Contribution to the decrease of the risk of osteoporosis [2];

Prebiotics can be found in some vegetables, such as leeks, onions, chicory, tomatoes, asparagus, artichokes, bananas, and alfalfa. It can also be added to industrial products such as foods for children, dairy and confectionery products, beverages, light mayonnaise and low-fat cheese, and they can be used as dietary supplements $[4,15]$.

Prebiotics are being used in the food industry as functional ingredients in beverages (fruit juices, coffee, cocoa, tea, soft drinks and alcoholic beverages), milk products (fermented milk, milk powder and ice cream), probiotic yogurts and symbiotic products [20,21]. Other applications include desserts (e.g., jellies, puddings, fruit-flavored ice cream), confectionery items (e.g., sweets), biscuits, breakfast cereals, chocolates, breads and pastas, meat products (e.g., fish paste) and tofu. Prebiotics can also be used in cosmetics, pharmaceuticals and products for people with diabetes [21].

\subsection{Fructooligosaccharides (FOS)}

Fructooligosaccharides (FOS) belong to the group of oligosaccharides and are isolated from plants. They consist of three to ten monosaccharide units joined by $\alpha$-glycosidic bonds (1-2) between terminal fructose and glucose [22].

The degree of polymerization (DP), defined by the number of monosaccharide units, is used to define and classify FOS and inulin molecules, with FOS having a DP $<10$ and inulin a DP between 2 - 60 [23]. The difference between inulin, oligofructose and synthetic fructooligosaccharides is the degree of polymerization, i.e., the number of individual monosaccharide units that make up the molecule [24]. In the extraction commercialization process, FOS can be obtained from inulin by means of the transfructosylation enzymatic reaction in sucrose residues by the action of the $\beta$-fructofuranosidase enzyme, with the DP of these products varying between 1 and 7 fructosyl units [25].

Flamm et al. [26] have evaluated the caloric value of FOS and found that the energy yield for the host would be in the range of $1.5 \mathrm{kcal} / \mathrm{g}$ to $2.0 \mathrm{kcal} / \mathrm{g}$. By using another method based on lipogenesis balance, Roberfroid [27] stated that the caloric value of FOS is around 1.0 $\mathrm{kcal} / \mathrm{g}$ to $1.5 \mathrm{kcal} / \mathrm{g}$.

FOS are available in some foods such as bananas, garlic, onion, tomato, wheat, asparagus, artichoke, leek, honey, rye, brown sugar, barley, triticale, beer, lettuce, chicory, burdock, beetroot, apples, bulbs like red lilies, yacon and oats, with onion being the food with the highest levels of FOS (Table 1).

In Holland, it is estimated that the consumption of FOS is $2 \mathrm{~g}$ to $12 \mathrm{~g}$ per day. In Japan, the estimate is between $13.7 \mathrm{mg} / \mathrm{kg}$ of body weight per day. However, for the approval of FOS, the Japanese law established the amount of $0.8 \mathrm{~g} / \mathrm{kg}$ of body weight per day as an acceptable daily intake $[29,30]$.

The average per capita daily consumption of FOS is 2 - $4 \mathrm{~g}$ for North Americans and 2 - $12 \mathrm{~g}$ for Europeans [31]. In Brazil, there are no relevant data regarding the amount consumed or the dietary recommendations.

The law considers FOS as ingredients of products, not additives. FOS are considered as dietary fiber, and in the United States, they have a GRAS status (Generally Recognized As Safe). Ingestion may cause flatulence, especially in individuals who have lactose intolerance, but the severity of this symptom is associated with the amount of FOS consumed: the higher the quantity, the greater the symptom [32].

The intake of $20 \mathrm{~g}$ to $30 \mathrm{~g}$ per day can promote severe discomfort in an individual, and thus, the optimal intake level is $10 \mathrm{~g}$ per day [30].

For the promotion of colon floral balance, the amount of FOS needed has been determined to be $2 \mathrm{~g}$ to $2.5 \mathrm{~g}$ per day [28]. The minimum dose of FOS for the induction of diarrhea is $44 \mathrm{~g}$ for men and $49 \mathrm{~g}$ for women $[23,33]$.

For enteral nutrition, several clinical studies suggest the amount of $5-10 \mathrm{~g} /$ day for the maintenance of normal

Table 1. Amount of FOS (\%) in some natural foods.

\begin{tabular}{cc}
\hline Food & Percentage, $\%$ \\
\hline Onion & 2.8 \\
Tomato & 1.8 \\
Rye & 0.7 \\
Banana & 0.3 \\
Garlic & 0.2 \\
\hline
\end{tabular}

Source: [28] 
flora and from $12.5 \mathrm{~g} /$ day to $20.0 \mathrm{~g}$ /day for bifidobacteria recovery [34].

In vitro and in vivo studies have suggested the lack of genotoxicity and mutagenicity of FOS.

Evaluations conducted in rats showed no adverse effects with quantities lower than $2.17 \mathrm{~g} / \mathrm{kg} /$ day $[23,35]$.

\subsection{Inulin}

Inulin is a linear polymer with b-glycosidic bonds $(2 \rightarrow$ 1) derived from D-fructose, it belongs to the fructan group and is synthesized by a variety of plants $[27,36]$.

Inulin is a reserve carbohydrate found in many plants. Many human foods contain inulin (Table 2), and among them, the onion stands out as a food that is highly consumed. The concentration of inulin in each plant depends on the variety, the time between harvesting and its use and storage conditions [37,38].

Functionally and technologically, the inulin extracted from plants passes through a drying process, presenting itself as an amorphous, hygroscopic white powder with neutral odor and taste. Inulin is used to enrich food products with fiber, maintaining the appearance and taste of standard formulations.

The average per capita consumption of inulin in the European diet varies from 2 to $12 \mathrm{~g} /$ day; it is around 5-8 $\mathrm{g} /$ day in Belgium and 7-12 g/day in Spain [41].

Studies in individuals of different ages have provided results that guarantee the safety of inulin and oligofructose [27]. Inulin has been used to evaluate the glomerular filtration rate by intravenous injection since 1931. This practice has become a standard procedure without toxic effects [42]. Additionally, based on the history of the use of foods containing inulin by humans, there is no evidence of toxic effects [43].

The dose of intolerance is quite high, which allows for a broad therapeutic dose range. Subjective gastrointestinal symptoms are difficult to measure $[24,44]$.

\subsection{Polydextrose (PDX)}

Polydextrose is a polysaccharide synthesized by the random polymerization of glucose in the presence of minor amounts of sorbitol and an acid catalyst (approximately $90: 10: 1$, respectively) under high temperature and partial vacuum [45].

The random linkages of the polydextrose polymer prevent digestive enzymes from hydrolyzing the molecule [46]. Thus, polydextrose is hard to digest in the small intestine after oral administration, with approximately $60 \%$ being excreted in the feces and $30 \%$ being fermented in the large intes tine by intes tinal microflora producing volatile fatty acids and $\mathrm{CO}_{2}$ [47].

According to Hara et al. [48], polydextrose is a dietary fiber that is not easily fermentable at only $1.0 \mathrm{kcal} / \mathrm{g}$; it is
Table 2. Quantity of inulin (\%) present in some foods.

\begin{tabular}{ccc}
\hline Plants & Edible part & Inulin (\%) \\
\hline Onion & Bulb & $2-6$ \\
Jerusalem Artichoke & Tubercle & $16-20$ \\
Chicory & Root & $15-20$ \\
Leek & Bulb & $3-10$ \\
Garlic & Bulb & $9-16$ \\
Artichoke & Central leaves & $3-10$ \\
Banana & Fruit & $0.3-0.7$ \\
Rye & Cereal & $0.5-1.0$ \\
Barley & Cereal & $0.5-1.5$ \\
Dandelion & Leaves & $12-15$ \\
Yacon & Root & $3-19$ \\
Goat's beard & Leaves & $4-11$ \\
Wheat & Cereal & $1-4$ \\
\hline
\end{tabular}

Source: $[39,40]$

very stable, has low viscosity and is widely distributed.

Polydextrose is partially fermented in the large intestine, increasing the amount of fecal mass, reducing transit time, softening and decreasing the $\mathrm{pH}$ of the fecal material. This fermentation leads to the growth of favorable microflora, reduction of putrefactive microflora, increased production of short chain fatty acids and elimination of carcinogenic metabolite production. In a human study, polydextrose increased intestinal function and ease of defecation. Furthermore, it inhibited the excessive absorption of glucose in the small intestine, and fermentation in the large intestine produced short chain fatty acids favoring the reduction of intestinal $\mathrm{pH}$. The daily intake of $4-12 \mathrm{~g}$ of polydextrose improved physiological function without producing adverse effects [45].

In an animal study, the ingestion of polydextrose (5 $\mathrm{g} / 100 \mathrm{~g}$ diet) increased the concentration of calcium in the bones of normal female rats, which may be relevant to decreasing the risk of osteoporosis [48].

A study with Chinese subjects in which the ingestion of polydextrose was administered in the amounts of 4,8 and $12 \mathrm{~g}$ daily, concluded that this ingestion provides effects similar to those of dietary fiber, without causing laxative problems [45].

With the Ordinance N. 29, dated January 13, 1998, the Brazilian National Health Surveillance Agency (ANVISA) determined that products must contain the label "This product may have a laxative effect", if they are products that are expected to be consumed at levels where the resulting daily intake may exceed $90 \mathrm{~g}$ of polydextrose [49].

\subsection{Galactooligosaccharides (GOS)}

Galactooligosaccharides (GOS) are also included among the non-digestible oligosaccharides (NDOs). GOS are 
composed of galactose molecules linked to lactose, consisting of tri- to hexasaccharides with 2-5 galactose units joined by $\beta$ bonds [50]. Its production occurs biochemically, when $\beta$-galactosidase acts as a hydrolytic enzyme and also as a condensing enzyme in a reaction called transgalactosylation [51].

GOS are defined as compounds that are not metabolized by the host and that reach the intestine to be metabolized by bifidobacteria. Dietary supplementation of these substances results in an increase in the occurrence and amount of bifidobacteria and inhibits the growth of pathogenic bacteria or putrefactive organisms that cause excessive production of gas [41].

GOS may be formed from lactose, and this is influenced by factors such as the source and concentration of the enzyme, $\mathrm{pH}$, temperature and substrate concentration $[52,53]$. The higher the amount of lactose, the greater the production of GOS [54,55].

To improve bacterial flora, the recommendation for GOS ingestion is $2 \mathrm{~g} /$ day to $3 \mathrm{~g} /$ day. For people with diabetes and high content of blood fat (cholesterol and triglycerides), the recommended amounts range from 8 $\mathrm{g} /$ day to $20 \mathrm{~g} /$ day [24].

Galactooligosaccharides do not present toxicity, and the only known adverse effect is diarrhea when GOS are consumed in excess, with the excess dose estimated at $0.3 \mathrm{~g} / \mathrm{kg}$ to $0.4 \mathrm{~g} / \mathrm{kg}$ of body weight [50].

\subsection{Xylooligosaccharides (XOS)}

The Xylooligosaccharides (XOS) are oligomers of unconventional sugars, formed by xylose units, which are non-caloric and not digestible by humans. They are found in fruits, vegetables, milk and honey.

The production of XOS occurs through the industrial production of lignocellulosic materials (LCMs), obtained from a variety of forest residues (eucalyptus wood) or agro-industries (corn cob, almond, olive, rice hulls, oats, barley) [56-58]. LCMs are composed of three basic polymers: lignin, cellulose and hemicellulose [59].

XOS improves food quality, providing a change in flavor and physico-chemical characteristics and stimulating the activity of Bifidobacterium in the intestinal tract [60].

The use of XOS as an ingredient in food products is due to their stability across a wide range of $\mathrm{pH}$ (2.5 to 8.0) and temperature, the selective metabolism by bifidobacteria, the increased production of volatile fatty acids, the reduction of stomach ulcer lesions [61] and the acceptable odor [62].

The use of these compounds presents an advantage over inulin in terms of resistance to acids in heating and the resistance to degradation in low $\mathrm{pH}$ juices and other carbohydrate beverages [41].
Xylobiose is also considered a Xylooligosaccharides (XOS) with a degree of polymerization of 2 [63]. It presents $30 \%$ of the sweetness of sucrose [64].

The recommended daily dose for XOS is $0.7 \mathrm{~g}$ [65].

\subsection{Lactulose}

Lactulose is a synthetic disaccharide composed of fructose and galactose, which is present in milk and dairy products that have undergone heat treatment [66].

During degradation, lactulose produces acidification of the intestinal environment and a decrease in $\mathrm{pH}$, responsible for triggering mechanisms that explain its action in portosystemic encephalopathy and constipation [67].

More recently, lactose has been used as a substrate for the production of bifidogenic factors in the form of lactulose, lactitol or lactosucrose. In general, bifidogenic factors are short-chain oligosaccharides (3 to 10 monosaccharide units) with the unique functional properties of not being digested in the stomach and small intestine. They serve as substrates and stimulate the growth of bifidobacteria and lactobacilli in the large intes tine, and further increas e $\mathrm{Ca}^{2+}$ and $\mathrm{Mg}^{2+}$ bioavailability, besides delaying or inhibiting certain stages of carcinogenesis $[68,69]$.

Lactulose is predominantly used as a pharmaceutical product that controls constipation [21].

The recommended starting dose is $10-30 \mathrm{ml}$ orally or by nasogastric tube (NG) 3-4 times per day until the beginning of the evacuations, and it can be administered as an enema (300 - $500 \mathrm{ml}$ of lactulose in 1 liter of filtered water), after which the dose can be adjusted in order to maintain 2 - 3 pasty stools/day [70].

The results of studies of acute, sub-chronic and chronic toxicity in many species indicate that lactulose has very low toxicity. The observed effects appear to be more related to the volume effect in the gastrointestinal tract than a more specific toxic activity [71].

\section{Beneficial Health Effects Related to the Ingestion of Prebiotics}

\subsection{Fructooligosaccharides (FOS)}

Several studies have demonstrated the functional properties of FOS, such as the reduction of cholesterol levels and blood glucose levels, lowering of blood pressure and better absorption of calcium and magnesium [72,73].

FOS are not digested by the human gastrointestinal tract, and when they reach the colon, they beneficially stimulate the growth and strengthening of specific bacteria in the intestine [20]. The bifidobacteria secrete $\beta$-fructosidase, which would be the enzyme responsible for FOS hydrolysis [27]. Gibson and Roberfroid [20] found the characteristics of bifidogenic FOS in humans using a 
dose of $15 \mathrm{~g}$ per day as dietary supplementation. The average counts of bifidobacteria increased, whereas there were significant reductions in Bacteroides, Fusobacterium and Clostridium sp. According to the authors, these compounds are utilized better by the bifidobacteria, whereas they cause unfavorable changes for harmful bacteria in the colon.

The mechanism by which the inhibition of pathogens occurs (exogenous or endogenous) can be explained by the lowering of the $\mathrm{pH}$ in the intestinal lumen as a consequence of the formation of short chain fatty acids (SCFA) by FOS fermentation $[19,27]$. The decrease in the number of harmful bacteria (such as Escherichia coli, Clostridium, Streptococcus faecallis and Proteus) results in the decrease in toxic metabolites, such as ammonia, indoles, phenols and nitrosamines [74].

Modler [41] verified that adding NeosugarR (a trade name of fructooligosaccharides) to the human diet (15 $\mathrm{g} /$ day) caused a tenfold increase in the population of bifidobacteria in the large intestine, as well as increasing the occurrence of bifidobacteria from $87 \%$ to $100 \%$. Concomitantly, there was a reduction of 0.3 intestinal $\mathrm{pH}$ units and a decrease in the enterobacteria count. Hidaka et al. [75] found that the administration of $8 \mathrm{~g} /$ day of Neosugar in the human diet increased the production of fatty acids. Wang and Gibson [19] found the following benefits could be attributed to bifidobacteria: they are immunomodulatory against malignant cells, produce $\mathrm{B}$ vitamins and folic acid, stimulate the production of digestive enzymes and lysozyme and restore normal intestinal biota after antibiotic therapy.

Regarding the bifidogenic dose of FOS, authors like Roberfroid et al. [76] established that about $4 \mathrm{~g}$ per day would be enough for an adult. Bouhnik [77] demonstrated that FOS ingestion at doses of $12.5 \mathrm{~g}$ /day for three days (clinically tolerated dose) produced a decrease in the total count of anaerobes in the feces, in $\mathrm{pH}$, in the activity of nitroreductase, in bile acid concentrations and in serum levels of total cholesterol and lipids.

\subsection{Inulin}

Experimental studies have shown that the application of inulin and oligofructose acts as bifidogenic factors. As a consequence of its use, there is a stimulation of the immune system of the host, a reduction in the levels of pathogenic bacteria in the intestine, constipation relief and a decreased risk of osteoporosis resulting from the stimulation of mineral absorption, particularly calcium. Thus, there would be a reduced risk of atherosclerosis by decreasing the synthesis of triglycerides and fatty acids in the liver and decreased levels of these compounds in the blood [2].

Studies with rats and hamsters and some with humans have shown that oligofructose and/or inulin increase calcium bioavailability. Increased calcium bioavailability could be due to the transfer of this mineral from the small intestine to the large intestine and the osmotic effect of inulin and oligofructose, which would transfer water into the large intestine, allowing calcium to become more soluble [78]. The improved bioavailability of calcium in the colon could also be derived from the hydrolysis of the calcium phytate complex by the action of bacterial phytases, liberating calcium. The better absorption was associated with a decrease in $\mathrm{pH}$ in the contents of the ileum, cecum and colon. This reduction results in increased concentration of ionized minerals, a condition that facilitates passive diffusion, the hypertrophy of the cecum walls and the increased concentration of volatile fatty acids, bile salts, calcium, phosphorus, phosphate and to a lesser degree, magnesium, in the cecum [2].

The hypolipidemic effect of inulin and oligofructose has been observed in some studies with rats, although it is controversial. Experimental data led us to hypothesize that FOS could reduce hepatic lipogenic capacity, through the inhibition of gene expression of lipogenic enzymes, resulting in reduced secretion of very low density lipoproteins (VLDL)-triacylglycerol. This inhibition could be achieved via production of short chain fatty acids or via insulin modulation by mechanisms not yet identified, but which are being investigated $[2,78,79]$. Future studies on the inulin hypolipidemic effect in humans should take into account the characteristics of the selected individuals, the duration of the study and the background of the subjects in terms of diet because these are important variables that can exert considerable influence on the enzymes [2].

Inulin influences intestinal function by increasing the frequency of bowel movements $[75,80]$, increasing stool weight in bowel movements (about 2 grams per gram of inulin or oligofructose ingested) [81] and reducing fecal $\mathrm{pH}$ due to fermentation $[20,80]$.

Research in experimental animal models has shown that inulin has anticarcinogenic properties [82]. In another study, the addition of inulin and oligofructose in the diet of rats reduced the colon carcinogenesis induced by azoxymethane [83].

The effect of a inulin enriched cookie was evaluate in obese patients on cardiovascular risk factors. No changes in anthropometrics parameters and the increase in soluble fiber intake did not produce any gastrointestinal adverse effect. The increase of fiber intake ( $3 \mathrm{~g}$ of inulin) from an enriched cookie reduced LDL cholesterol levels in obese patients [84].

\subsection{Polydextrose (PDX)}

Polydextrose is partially fermented in the large intestine, 
increasing the amount of fecal mass, reducing transit time, softening and decreasing the $\mathrm{pH}$ of fecal material. This fermentation leads to the growth of favorable microflora, reduction of putrefactive microflora, increased production of short chain fatty acids and elimination of carcinogenic metabolite production [45]. The large intestine has the capacity to absorb calcium, and the microbial fermentation after ingestion of fermentable material is considered the mechanism responsible for increased calcium absorption in the intestine [48].

In a study with humans, polydextrose favored intestinal function and improved ease of defecation. Furthermore, it inhibited the increased absorption of glucose in the small intestine, and the fermentation in the large intestine produced short chain fatty acids favoring the reduction of gut $\mathrm{pH}$. Therefore, the daily intake of $4-12 \mathrm{~g}$ of polydextrose improves the physiological function without producing adverse effects [45].

In an animal study, the ingestion of polydextrose (5 $\mathrm{g} / 100 \mathrm{~g}$ diet) increased the concentration of calcium in the bones of normal female rats, which may be relevant to the decrease in the risk of osteoporosis [48].

Santos et al. [85] showed in a study to verify if polydextrose could stimulate calcium absorption in partially gastrectomized and sham operated rats that the polydextrose feeding $(50 \mathrm{~g} / \mathrm{kg}$ of diet) increased calcium absorption and bone calcium concentration in normal rats and the partially gastrectomy did not affect the bone calcium concentration. In a recent study, Santos et al. [86] investigated whether polydextrose stimulates iron absorption in rats submitted to partial gastrectomy and sham operated and the diet with polydextrose reduced the excretion of iron and apparent iron absorption was higher in the polydextrose fed groups than in the control group.

\subsection{Galactooligosaccharides (GOS)}

The ingestion of GOS promotes the proliferation of bifidobacteria and the reduction of deteriorating bacteria, thus causing beneficial effects to human health, such as liver detoxification by the reduction of toxic metabolites; prevention of pathogenic diarrhea due to short-chain fatty acid production by bifidobacteria; aid in cases of constipation; increased lactose tolerance; increased bone mineralization and fracture resistance caused by the stimulation of calcium absorption, which could possibly reduce the risk of osteoporosis [87]. According to Chonan and Watanuki [88], calcium absorption in rats was stimulated by administering feed containing GOS.

In a study performed with 90 children to determine the effect of a mixture of two prebiotics, fructooligosaccharides (FOS) and galactooligosaccharides (GOS), stool samples were collected for colony forming units (CFU) count and $\mathrm{pH}$ influence. Various doses and times were tested, with the objective of verifying the best conditions. The dose of $0.8 \mathrm{~g}$ of GOS per $\mathrm{kg}$ of body weight was the most suitable when compared with the placebo formula (maltodextrin-based). The mixture of GOS and FOS had a stimulating effect on the growth of Bifidobacterium and Lactobacillus in the intestine and was very promising for the use of supplements to infant formulas [89].

Perez-Conesa et al. [90] studied seven groups of rats that were fed for one month, where one group received an infant formula containing Bifidobacterium bifidum and Bifidobacterium longum, three groups received infant formula containing 4 ' galactosyl-lactose (GOS) at $1.2 \%, 5.0 \%$ and $10.0 \%$, and three groups received infant formulas containing both ingredients during three periods of observation. Results showed that the proportion of bifidobacteria was greater than the anaerobic bacteria in the 1st period. In the 2 nd period, the bifidobacteria decreased significantly, and in the 3rd period, the bifidobacteria count increased, especially in the group fed with a diet containing $1.2 \%$ of GOS.

The addition of the inulin/GOS mixture were demonstrated in several studies with infants and children as the increasing of the faecal percentage of Bifidobacteria population in the fecal flora with addition of the inulin/GOS mixture [91], significantly decreased the episodes of gastrointestinal and respiratory tract infections [92], the increasing faecal immunoglobulin levels (Ig) [93], a positive effects indicated by a lower incidence of febrile episodes in infants [94] and a beneficial effect on the immune system of preterm infants after administration of the combination of neutral oligosaccharides with acidic oligosaccharides (maximal dose of $1.5 \mathrm{~g} / \mathrm{kg} /$ day added to breast milk or preterm formula) [95].

In a study conducted to determine the effect of supplementation with GOS and polydextrose (PDX) in calcium and iron absorption in gastrectomized rats, it was concluded that supplementation with both of the prebiotics increased the serum iron by $15 \%$ in non-gastrectomized animals $(2.5 \%$ GOS $+2.5 \%$ PDX) compared with the control non-gastrectomized animals (diet without prebiotic), and 5\% PDX increased the apparent absorption in gastrectomized rats. Daily administration of 5\% GOS and 5\% PDX increased the apparent absorption of calcium in control rats. There is strong evidence that the two prebiotics act synergistically, with increased prebiotic effects [96].

A prebiotic galacto-oligosaccharide mixture (B-GOS) was assessed the effectiveness on the severity and/or incidence of travellers' diarrhoea (TD) in 159 healthy subjects, who travelled for a minimum of 2 weeks to a country of low or high risk for TD. The placebo was maltodextrin. The authors found significant differences between the B-GOS and the placebo group in the inci- 
dence, duration, on abdominal pain and the overall quality of life assessment. According to Drakoularakou et al. [97], the tested galacto-oligosaccharide mixture showed significant potential in preventing the incidence and symptoms of TD.

\subsection{Xylooligosaccharides (XOS)}

The health effects of Xylooligosaccharides have mainly focused on the effects on the intestinal flora [98,99].

Results were obtained in vivo using rats, with considerable growth of Bifidobacterium ssp. in the gastrointestinal tract [100] and the increase of total short chain fatty acids in the rats' cecum [101,102]. Tests in humans showed that the ingestion of XOS benefits the intestinal flora, where the ingested xylobiose (X2) was not excreted in the feces and urine within 24 hours following an oral administration. These compounds are not hydrolyzed by saliva, pancreatic and gastric juice, which suggest the use of XOS by the intestinal bacteria [103].

The digestibility of XOS in the gastrointestinal tract and its effect on the absorption of bile acids are compared to the effects of FOS and isomaltooligosaccharides (IOS). Considering digestibility, HPLC analyses showed the hydrolysis of FOS, IOS and XOS products after 4 hours of digestion in vitro; most of the IOS and part of the FOS was digested by the intestinal juice, while XOS was not digested by any digestive enzyme. The delay in the effects of XOS on bile acid absorption compared with IOS and FOS were confirmed in in vitro experiments [104].

In vitro assays have shown that Bifidobacterium spp. and B. adolescentis are active consumers of XOS (x2 and $\mathrm{x} 3$ ); the oral absorption of XOS stimulated the proliferation of Bifidobacterium bifidum in the intestine, but not Staphylococcus, E. coli and species of Clostridium spp. that did not use XOS [100,103].

Most species of Lactobacillus used XOS, including $L$. fermentum, which demonstrated this ability, and although Bacteroides used XOS, it did so only on a small scale compared with glucose [103].

When prebiotics were compared, the Bifidobacterium spp. preferred XOS, raffinose and FOS over hexoses, with XOS being more effective than raffinose and as effective as FOS in in vitro growth experiments [105].

Rycroft et al. [106] evaluated the fermentative properties of some prebiotics; they found that XOS and lactulose produced the highest increases in the number of bifidobacteria and that while FOS led to the development of lactobacilli, a mixture could increase the functionality.

A study to assess the effects of XOS on the intestinal microbiota, gastrointestinal function and nutritional parameters in elderly patients suggested a XOS daily dose of $4 \mathrm{~g}$ in a three-week period. The study concluded that
XOS supplementation promoted intestinal health and showed no adverse effects on the nutritional status of the elderly [107].

In a recent study, Makelainen et al. [108] realized the fermentation of two new hard-wood derived xylooligosaccharides, xylan and a commercial XOS preparation by human microbiota in a human colon simulator (EnteromixR). The xylooligosaccharides were fermented selectively by Bifidobacterium lactis strains and FOS were used as a prebiotic reference. XOS was more efficient than FOS in increasing the numbers of $B$. lactis in the colonic model. The combination of XOS and B. lactis might be possible to formulate strain-specific synbiotic product with selective properties on desired probiotics.

\subsection{Lactulose}

Studies using lactulose have shown that it contributes to the increased population of beneficial bacteria in the intestine at the expense of putrefactive bacteria or other bacteria [77].

In a study of the incorporation of $0.5 \%$ of lactulose in formulations for infants, it was found that this quantity promoted changes in the microbiota, predominantly of bifidobacteria, while the control formulas caused the microbiota to consist of coliforms [66].

In patients with long-standing liver cirrhosis, the administration of milk fermented with bifidobacteria and lactulose resulted in the re-stabilization of beneficial microbiota of the intestine, along with the reduction of ammonia and free phenols in the blood [109].

Lactulose has been widely used in the treatment of hepatic encephalopathy, decreasing the concentration of ammonia in the blood and preventing the development of this pathology [110,111].

\section{Industrialized Foods with Prebiotic Addition}

The health effect of food is a major determining factor in whether to purchase a food item. The food industry has invested in some great innovations, mainly in the formulation of ingredients and additives, functional foods, transgenic foods and packaging [112]. The increased demand for functional foods in recent years is closely related to the growing concern of society with health and quality of life. Moreover, consumers are more informed and aware about the foods that can benefit health.

Several industrial products containing added prebiotics can be found in the consumer market: dairy products, breads, fruit juices, margarine, pasta, dairy desserts, ice creams, cereals, milk, yogurt, biscuits, soft drinks in general, isotonic drinks, liquid sugar and modified sugar, chocolates and candies in general. 


\section{Conclusion}

The various studies in clinical nutrition conducted over the past 20 years have established the indirect role of prebiotic ingredients in promoting healthy and balanced intestinal microbiota.

In addition, the administration of prebiotics reduces blood lipids and blood pressure, increases the synthesis and absorption of nutrients and has anti-carcinogenic action. In addition to its functional properties, prebiotics show interesting properties that have implications for the food processing industry and the content of its end-products.

The proper administration of prebiotics consists of following the recommended daily intake, which should be specific to the pathology indicated and at levels that do not cause side effects.

\section{REFERENCES}

[1] C. M. Hasler, "Functional Foods: Their Role in Disease in: Developing New Food Products for a Changing Prevention and Health Promotion," Food Technology, Vol. 52, No. 2, 1998, pp. 57-62.

[2] N. Kaur and A. K. Gupta, "Applications of Inulin and Oligofructose in Health and Nutrition," Journal of Bioscience, Vol. 27, No. 7, 2002, pp. 703-714. doi:10.1007/BF02708379

[3] D. F. C. Anjo, "Alimentos Funcionais em Angiologia e Cirurgia Vascular," Jornal Vascular Brasileiro, Vol. 3, No. 2, 2004, pp. 431-437.

[4] M. H. Saier Jr. and N. M. Mansour, "Probiotics and Prebiotics in Human Health," Journal of Molecular Microbiology and Biotechnology, Vol. 10, No. 1, 2005, pp. 22-25. doi:10.1159/000090345

[5] D. Bosscher, J. Loo-Van and A. Franck, "Inulin and Oligofructose as Prebiotics in the Prevention of Intestinal Infections and Diseases," Nutrition Research Reviews, Vol. 19, No. 2, 2006, pp. 216-226. doi:10.1017/S0954422407249686

[6] J. Huebner, R. L. Wehling and R. L. Hutkins, "Functional Activity of Commercial Prebiotics," International Dairy Journal, Vol. 17, No.7, 2007, pp. 770-775. doi:10.1016/j.idairyj.2006.10.006

[7] M. B. Roberfroid, "Prebiotics: The Concept Revisited," The Journal of Nutrition, Vol. 137, No. 3, 2007, pp. 830S-837S.

[8] M. R. Urgell, A. S. Orleans and M. R. P. Seuma, "La Importancia de los Ingredientes Funcionales en las Leches y Cereales Infantiles," Nutricion Hospitalaria, Vol. 20, No. 2, 2005, pp.135-146.

[9] Y. C. Cao and A. F. Fernandez, "Probioticos y Salud: Una Reflexion Necesaria," Revista Cubana Medicina General Integrada, Vol. 21, No. 3-4, 2005, pp. 3-4.

[10] R. P. Quera, E. Quigley and A. M. S. Madrid, "El rol de los Prebioticos, Probioticos y Simbioticos en Gastroen- terologia," Gastroenterology Latinoamerican, Vol. 16, No. 3, 2005, pp. 218-228.

[11] V. C. Sgarbieri and M. T. B. Pacheco, "Alimentos Funcionais Fisiologicos," Brazilian Journal of Food Technology, Vol. 2, No. 1-2, 1999, pp. 7-19.

[12] L. P. Silva and J .L. Nornberg, "Prebioticos na Nutricao de nao Ruminantes," Ciencia Rural, Vol. 33, No. 5, 2003, pp. 983-990.

[13] G. R. Gibson and R. Fuller "Aspects of In Vitro and In Vivo Research Approaches Directed toward Identifying Probiotics and Prebiotics for Human Use," The Journal of Nutrition, Vol. 130, No. 2, 2000, pp. 391S- 395S.

[14] T. S. Manning and G. R. Gibson, "Prebiotics," Best Practice and Research Clinical Gastroenterology, Vol. 18, No. 2, 2004, pp. 287-298. doi:10.1016/j.bpg.2003.10.008

[15] P. R. Arabbi, "Alimentos Funcionais: Aspectos Gerais," Nutrire, Vol. 21, No. 6, 2001, pp. 87-102.

[16] A. C. Ouwehand, M. Derrien, W. de Vos, K. Tiihonen and N. Rautonen, "Prebiotics and Other Microbial Substrates for Gut Functionality," Current Opinion in Biotechnology, Vol. 16, No. 2, 2005, pp. 212-217. doi:10.1016/j.copbio.2005.01.007

[17] S. Macfarlane, G. T. Macfarlane and J. H. Cummings, "Review Article: Prebiotics in the Gastrointestinal Tract," Alimentary Pharmacology and Therapies, Vol. 24, No. 5, 2006, pp. 701-714. doi:10.1111/j.1365-2036.2006.03042.x

[18] M. A. Losada and T. Olleros, "Towards a Healthier Diet for the Colon: The Influence of Fructooligosaccharides and Lactobacilli on Intestinal Health," Nutrition Research, Vol. 22, No. 1, 2002, pp. 71-84. doi:10.1016/S0271-5317(01)00395-5

[19] X. Wang and G. R. Gibson, "Effects of the In Vitro Fermentation of Oligofructose and Inulin by Bacteria Growing in the Human Large Intestine," Journal of Applied Bacteriology, Vol. 75, No. 4, 1993, pp. 373-380.

[20] G. R. Gibson and M. B. Roberfroid, "Dietary Modulation of the Human Colonic Microbiota-introducing the Concept of Prebiotics," The Journal of Nutrition, Vol. 125 , No. 6, 1995, pp. 1401-1412.

[21] S. I. Mussatto and I. M. Mancilha, "Non-digestible Oligosaccharides: A Review," Carbohydrate Polimers, Vol. 68, No. 3, 2007, pp. 587-597. doi:10.1016/j.carbpol.2006.12.011

[22] A. Tamine, V. Marshall and R. Robinson, "Microbiological and Technological Aspects of Milks Fermented by Bifidobacteria," Journal of Dairy Research, Vol. 62, No. 1, 1995, pp. 151-187. doi:10.1017/S002202990003377X

[23] J. E. Spiegel, R. Rose, P. Karabell, V. H. Frankos and D. F. Schmitt, "Safety and Benefits of Fructooligosaccharides as Food Ingredients," Food Technology, Vol. 48, No.1, 1994, pp.85-89.

[24] I. G. Carabin and W. G. Flamm, "Evaluation of Safety of Inulin and Oligofructose as Dietary Fiber," Regulatory Toxicology and Pharmacology, Vol. 30, No. 3, 1999, pp. 
268-282. doi:10.1006/rtph.1999.1349

[25] V. C. Borges, "Impacto dos Alimentos Para a Saude," Nutricao em Pauta, No. 48, 2001, pp. 17-18.

[26] G. Flamm, W. Glinsmann, D. Kritchevsky, L. Prosky and M. B. Roberfroid, "Inulin and Oligofructose as Dietary Fiber: A Review of the Evidence," Critical Reviews in Food Science and Nutrition, Vol. 41, No. 5, 2001, pp. 353-362. doi:10.1080/20014091091841

[27] M. B. Roberfroid, "Dietary Fiber, Inulin, and Oligofructose: A Review Comparing Their Physiological Effects," Critical Reviews in Food Science and Nutrition, Vol. 33, No. 2, 1993, pp. 103-148. doi:10.1080/10408399309527616

[28] V. C. Borges, "Oligassacarideos x Fibras Alimentares," Revista Brasileira de Nutricao Clinica, Vol. 12, No. 2, 1997, pp. 161-164.

[29] L. M. L. Passos and Y. K. Park, "Fructooligosaccharides: Implications in Human Health Being and Use in Foods," Ciencia Rural, Vol. 33, No. 2, 2003, pp. 385-390.

[30] K. M. Tuohy, G. C. M. Rouzaud, W. M. Bruck and G. R. Gibson, "Modulation of the Human Gut Microflora towards Improved Health Using Prebiotics - Assessment of Efficacy," Current Pharmaceutical Design, Vol. 11, No. 1, 2005, pp. 75-90. doi:10.2174/1381612053382331

[31] G. R. Gibson, C. L. Willis and J. Van Loo, "Non-digestible Oligosaccharides and Bifidobacteria Implications for Health," International Sugar Journal, Vol. 96, No. 1150, 1994, pp. 381-387.

[32] M. C. O. Hauly and J. A. Moscatto, "Inulin and Oligofructosis: A Review about Functional Properties, Prebiotic Effects and Importance for Food Industry," Semina: Ciencias Exatas e Tecnologicas, Vol. 23, No. 1, 2002, pp. 105-118.

[33] G. P. Costa and D. L. Waitzberg, "Efeitos Beneficos dos Frutooligossacarideos na Saude Humana," Revista Brasileira de Medicina, Vol. 1, No. 7, 1997, pp. 6-7.

[34] P. M. Lima, "FOS em Nutricao Enteral," Revista Qualidade em Alimentacao - Nutricao, Vol. 4, No. 15, 2003, pp. 26-27.

[35] T. Tokunaga, T. Oku and N. Hosya, "Utilization and Excretion of a New Sweetener Fructooligosaccharide (Neosugar) in Rats," The Journal of Nutrition, Vol. 119, No. 4, 1989, pp. 553-559.

[36] N. C. Carpita, J. Kamabus and T. L. Housley, "Linkage Structure of Fructans and Fructan Oligomers from Triticum Astivum and Fistuca Arundinaceae Leaves," Journal of Plant Physiology, Vol. 134, No. 2, 1989, pp. 162-168.

[37] P. P. Rutherford and R. Whittle, "The Carbohydrate Composition of Onions during Long Term Cold Storage," Journal of Horticultural Science and Biotechnology, Vol. 57, No. 3, 1982, pp. 349-356.

[38] M. Suzuki and J. A. Cutclife, "Fructan in Onion Bulbs in Relation to Storage Life," Canadian Journal of Plant Science, Vol. 69, No. 4, 1989, pp.1327-1333. doi:10.4141/cjps89-160

[39] J. van Loo, P. Coussement, L. Deleenheer, H. Hoebregs and G. Smits, "On the Presence of Inulin and Oligofructose as Natural Ingredients in the Western Diet," Critical Reviews in Food Science Nutrition, Vol. 35, No. 6, 1995, pp. 525-552.

[40] A. J. Moshfegh, J. E. Friday, J. P. Goldman and J. K. C. Ahuja, "Presence of Inulin and Oligofructose in Diets of Americans," The Journal of Nutrition, Vol. 129, No. 7, 1999, pp. 1407-1411.

[41] H. W. Modler, "Bifidogenic Factors - Sources, Metabolism and Applications," International Dairy Journal, Vol. 4, No. 5, 1994, pp. 383-407. doi:10.1016/0958-6946(94)90055-8

[42] M. Price, R. Schwartz and H. Hoyt, "Evaluation and Characteristics of Currently Available Inulin," Investigative Urology, Vol. 16, No. 1, 1978, pp. 13-14.

[43] P. A. Coussement, "Inulin and Oligofructose: Safe Intakes and Legal Status," The Journal of Nutrition, Vol. 129, No. 7, 1999, pp. 1412-1417.

[44] W. H. Holzapfel and U. Schillinger, "Introduction to Preand Probiotics," Food Research International, Vol. 35, No. 2-3, 2002, pp. 109-116. doi:10.1016/S0963-9969(01)00171-5

[45] Z. Jie, L. Bang-Yao, X. Ming-Jie, L. Hai-Wei, Z. Zu-Kang, W. Ting-Song and S. A. Craig, "Studies on the Effects of Polydextrose Intake on Physiologic Functions in Chinese People," American Journal of Clinical Nutrition, Vol. 72, No. 6, 2000, pp. 1503-1509.

[46] O. Murphy, "Non-polyol Low-digestible Carbohydrates: Food Applications and Functional Benefits," The British Journal of Nutrition, Vol. 85, No. supplement 1, 2001, pp. S47-S53. doi:10.1079/BJN2000261

[47] M. Yoshioka, Y. Shimomura and M. Suzuki, "Dietary Polydextrose Affects the Large Intestine in Rats," The Journal of Nutrition, Vol. 124, No. 4, 1994, pp. 539-547.

[48] H. Hara, T. Suzuki and Y. Aoyama, "Ingestion of the Soluble Dietary Fibre, Polydextrose, Increases Calcium Absorption and Bone Mineralization in Normal and Total-gastrectomized Rats," The British Journal of Nutrition, Vol. 84, No. 5, 2000, pp. 655-661.

[49] Agencia Nacional de Vigilancia Sanitaria (ANVISA). Portaria no 29, de 13 de janeiro de 1998. Aprova o Regulamento Tecnico referente a Alimentos para fins especiais. D.O.U. - Diarios Oficial da Uniao. Poder Executivo. De 30 de marco de 1998.

Internet Available: <http://e-legis.bvs.br/leisref/public>. Assessed in July 25, 2010.

[50] T. Sako, K. Matsumoto and R. Tanaka, "Recent Progress on Research and Applications of Nondigestible Galacto-oligosaccharides," International Dairy Journal, Vol. 9, No. 1, 1999, pp. 69-80. doi:10.1016/S0958-6946(99)00046-1

[51] J. E. Prenosil, E. Stuker and J. R. Bourne, "Formation of Oligosccharides during Enzymatic Lactose Hydrolysis and Their Importance in a Whey Hydrolysis Process: Part II: Experimental," Biotechnology and Bioengineering, Vol. 30, No. 9, 1987, pp. 1026-1031. doi:10.1002/bit.260300905 
[52] R. R. Mahoney, "Galactosyl-oligosaccharide Formation during Lactose Hydrolysis - A Review," Food Chemistry, Vol. 63, No. 2, 1998, pp. 147-154. doi:10.1016/S0308-8146(98)00020-X

[53] I. Y. S. Rustom, M. I. Foda and M. H. L. Leiva, "Formation of Oligosaccharides from Whey UF-permeate by Enzymatic Hydrolysis: Analysis of Factors," Food Chemistry, Vol. 62, No. 2, 1998, pp. 141-147. doi:10.1016/S0308-8146(97)00203-3

[54] M. H. L. Leiva and M. Guzman, "Formation of Oligosaccharides during Enzymic Hydrolysis of Milk Whey Permeates," Process Biochemistry, Vol. 30, No. 8, 1995, pp. 757-762. doi:10.1016/0032-9592(95)00006-H

[55] D. Roy, L. Daoudi and A. Azaola, "Optimization of Galacto-oligosaccharides Production by Bifidobacterium Infantis RW-8120 Using Response Surface Methodology," Journal of Industrial Microbiology and Biotechnology, Vol. 29, No. 5, 2002, pp. 281-285. doi:10.1038/sj.jim.7000319

[56] D. V. Evtuguim, J. L. Tomas, A. M. Silva and C. Pascoal Neto, "Characterization of an Acetylated Heteroxylan from Eucalyptus Globulus Labill," Carbohydrate Research, Vol. 338, No. 7, 2003, pp. 597-604. doi:10.1016/S0008-6215(02)00529-3

[57] P. Moura, R. Barata, F. Carvalheiro, F. Girio, M. C. Loureiro-Dias and M. P. Esteves, "In Vitro Fermentation of Xylooligosaccharides from Corn Cobs Autohydrolysis by Bifidobacterium and Lactobacillus Strains," LWT Food Science and Technoology, Vol. 40, No. 6, 2007, pp. 963-972.

[58] D. Nabarlatz, A. Ebringerova and D. Montane, "Autohydrolysis of Agricultural Byproducts for the Production of Xylo-oligosaccharides," Carbohydrate Polymers, Vol. 69, No. 1, 2007, pp. 20-28. doi:10.1016/j.carbpol.2006.08.020

[59] G. Garrote, H. Dominguez and J. C. Parajo, "Mild Autohydrolysis: An Environmentally Friendly Technology for Xylooligosaccharide Production from Wood," Journal of Chemical Technology and Biotechnology, Vol. 74, No. 11, 1999, pp.1101-1109.

doi:10.1002/(SICI)1097-4660(199911)74:11<1101::AIDJCTB146>3.0.CO;2-M

[60] H. Nakano, "Recent Japanese Development in the Enzymatic Production and Application of Oligosaccharides," Presented at the Seminar on Enzyme and Bacterial Technology, 1998, Campinas. Japan International Cooperation Agency (s.d).

[61] J. C. Parajo, G. Garrote, J. M. Cruz and H. Dominguez, "Production of Xylooligosaccharides by Autohydrolysis of Lignocellulosic Materials," Trends in Food Science and Technology, Vol. 15, No. 3-4, 2004, pp. 115-120. doi:10.1016/j.tifs.2003.09.009

[62] C. Hsu, J. W. Liao, Y. C. Chung, C. P. Hsieh and Y. C. Chan, "Xylooligosaccharides and Frutooligosaccharides Affect the Intestinal Microbiota and Precancerous Colonic Lesion Development in Rats," The Journal of Nutrition, Vol. 134, No. 6, 2004, pp. 1523-1528.

[63] I. Tateyama, K. Hashii, I. Johno, T. Ino, K. Hirai, Y.
Suwa and Y. Kiso, "Effect of Xylooligosaccharide Intake on Severe Constipation in Pregnant Women," Journal of Nutrition Science Vitaminology, Vol. 51, No. 6, 2005, pp. 445-448.

[64] M. K. Bhat, "Oligossaccharides as Functional Food Ingredients and Their Role in Improving the Nutritional Quality of Human Food and Health," Recent Research Developments Agricultural and Food Chemistry, Vol. 2, 1998, pp. 787-802.

[65] H. Tomomatsu, "Health Effects of Oligosaccharides," Food Technology, Vol. 48, No. 10, 1994, pp. 61-65.

[66] R. Nagendra, S. Viswanatha, S. Arun Kumar, B. Krishna Murthy and S. Venkat Rao, "Effect of Feeding Milk Formula Containing Lactulose to Infants on Faecal Bifidobacterial Flora," Nutrition Research, Vol. 15, No. 1, 1995, pp. 15-24. doi:10.1016/0271-5317(95)91649-W

[67] C. Schumann, "Medical, Nutritional and Technological Properties of Lactulose. An Update," European Journal of Nutrition, Vol. 41, No. supplement 1, 2002, pp. 17-25. doi:10.1007/s00394-002-1103-6

[68] T. Oku, "Special Physiological Functions of Newly Developed Mono and Oligosaccharides," In: I. Goldberg, Ed., Functional Foods, Chapman and Hall, New York, 1994, pp. 202-218.

[69] J. N. Young, "Developments in Probiotics, Prebiotics and Synbiotics," IFT Annual Meeting, Orlando, 1997, pp. 93-97.

[70] S. Sherlock and J. Dooley, "Hepatic Encephalopathy," In: S. Sherlock and J. Dooley, Eds., Disease of the Liver and Biliary System, 11a ed., Blackwell Publishing, Oxford, 2002, pp. 93-110.

[71] Vademecum Hospitalar. Lactulose Generis. Internet Available:

$<$ http://st2.medicom.es/mono_output/mono_m5564?id_m on $=5564<$ Assessed on July 27, 2010.

[72] D. I. A. Pereira and G. R. Gibson, "Effects of Consumption of Probiotics and Prebiotics on Serum Lipid Levels in Humans," Critical Reviews in Biochemistry and Molecular Biology, Vol. 37, No. 4, 2002, pp. 259-281. doi:10.1080/10409230290771519

[73] C. Coundray, C. Demigne and Y. Rayssiguier, "Effects of Dietary Fiber on Magnesium Absorption in Animals and Humans," The Journal of Nutrition, Vol. 133, No. 1, 2003, pp. 1-4.

[74] J. H. Cummings, G. T. MacFarlane and H. Englyst, "Prebiotic Digestion and Fermentation," American Journal of Clinical Nutrition, Vol. 73, No. 2, 2001, pp. 415-420.

[75] H. Hidaka, T. Eida, T. Takizawa, T. Tokunaga and Y. Tashiro, "Effects of Fructooligosaccharides on Intestinal Flora and Human Health," Bifidobacteria and Microflora, Vol. 5, No. 1, 1986, pp. 37-50.

[76] M. B. Roberfroid, J. A. E. Van Loo and G. R. Gibson, "The Bifidogenic Nature of Chicory Inulin and Its Hydrolysis Products," The Journal of Nutrition, Vol. 128, No. 1, 1998, pp. 11-19.

[77] Y. Bouhnik, "Effects of Fructooligosaccharides Ingestion on Fecal Bifidobacteria and Selected Metabolic Indexes 
of Colon Carcinogenesis in Healthy Humans," Nutrition and Cancer, Vol. 26, No. 1, 1996, pp. 21-29. doi:10.1080/01635589609514459

[78] M. B. Roberfroid, "Functional Food Concept and Its Application to Prebiotics," Digestive and Liver Disease, Vol. 34, No. supplement 2, 2002, pp. 105-110. doi:10.1016/S1590-8658(02)80176-1

[79] N. M. Delzenne, C. Daubioul, A. Neyrinck, M. Lasa and H. S. Taper, "Inulin and oligofructose modulate lipid metabolism in animals: review of biochemical events and future prospects," British Journal of Nutrition, Vol. 87, No. supplement 2, 2002, pp. S255-S259. doi:10.1079/BJN/2002545

[80] E. Menne, N. Guggenbuhl and M. B. Roberfroid, "Fn-type Chicory Hydrolysate Inulin has a Prebiotic Effect in Humans," The Journal of Nutrition, Vol. 130, No. 5, 2000, pp. 1197-1199.

[81] T. Oku, "Special Physiological Functions of Newly Developed Mono and Oligosaccharides," In: I. Goldberg, Functional Foods, Chapman and Hall, New York, 1994, pp. 202-218.

[82] B. Pool-Zobel, J. Van Loo, I. Rowland and M. B. Roberfroid, "Experimental Evidences on the Potential of Prebiotic Fructans to Reduce the Risk of Colon Cancer," The British Journal of Nutrition, Vol. 87, No. 2, 2002, pp. 273-281.

[83] A. P. Femia, C. Luceri, P. Dolara, A. Giannini, A. Biggeri, M. Salvadori, Y. Clune, K. J. Collins, M. Paglierani and G. Caderni, "Antitumorigenic Activity of the Prebiotic Inulin Enriched with Oligofructose in Combination with the Probiotics Lactobacillus Rhamnosus and Bifidobacterium Lactis on Azoxymethane-Induced Colon Carcinogenesis in Rats," Carcinogenesis, Vol. 23, No. 11, 2002, pp. 1953-1960. doi:10.1093/carcin/23.11.1953

[84] D. A. de Luis, B. de la Fuente, O. Izaola, R. Conde, S. Gutierrez, M. Morillo and C. Teba Torres, "Randomized Clinical Trial with a Inulin Enriched Cookie on Risk Cardiovascular Factor in Obese Patients," Nutricion Hospitalaria, Vol. 25, No. 1, 2010, pp. 53-59.

[85] E. F. dos Santos, K. H. Tsuboi, M. R. Araujo, A. C. Ouwehand, N. A. Andreollo and C. K. Miyasaka, "Dietary Polydextrose Increases Calcium Absorption in Normal Rats," Arquivos Brasileiros de Cirurgia Digestiva, Vol. 22, No. 4, 2009, pp. 201-205.

[86] E. F. dos Santos, K. H. Tsuboi, M. R. Araujo, M. A. Falconi, A. C. Ouwehand, N. A. Andreollo and C. K. Miyasaka, "Ingestion of Polydextrose Increase Iron Absorption in Rats Submitted to Partial Gastrectomy," Acta Cirurgica Brasileira, Vol. 25, No. 6, 2010.

[87] F. Brouns and C. Vermeer, "Functional Food Ingredients for Reducing the Risks of Osteoporosis," Trends in Food Science and Technology, Vol. 11, No. 1, 2000, pp. 22-33. doi:10.1016/S0924-2244(99)00052-7

[88] O. Chonan and M. Watanuki, "The Effect of 6'-galactooligosaccharides on Bone Mineralization of Rats Adapted to Different Levels of Dietary Calcium," International Journal for Vitamin and Nutrition Research, Vol. 66, No. 3, 1996, pp. 244-249.
[89] G. Moro, I. Minoli, M. Mosca, S. Fanaro, J. Jelinek, B. Stahl and G. Boehm, "Dosage-related Bifidogenic Effects of Galacto- and Fructooligosaccharides in Formula-Fed Term Infants," Journal of Pediatric Gastroenterology and Nutrition, Vol. 34, No. 3, 2002, pp. 291-295. doi:10.1097/00005176-200203000-00014

[90] D. Perez-Conesa, G. Lopez, G. Ros, P. Abellan and R. Hartemink, "Faecal Microbiota Changes with the Consumption of Follow-Up Formulas Containing Bifidobacterium Spp. and/or Galactooligosaccharides by Rats and a Follow-Up Infant Formula Containing Bifidobacterium Spp. by Human Infants," Journal of Food Science, Vol. 71, No. 1, 2006, pp. M7-M13. doi:10.1111/j.1365-2621.2006.tb12396.x

[91] P. A. Scholtens, M. S. Alles, J. G. Bindels, E. G. Van der Linde, J. J. Tolboom and J. Knol, "Bifidogenic Effects of Solid Weaning Foods with Added Prebiotic Oligosaccharides: A Randomized Controlled Clinical Trial," Journal of Pediatric Gastroenterology and Nutrition, Vol. 42, No. 5, 2006, pp. 553-559. doi:10.1097/01.mpg.0000221887.28877.c7

[92] E. Bruzzese, M. Volpicelli, F. Salvini, M. Bisceglia, P. Lionetti, M. Cinquetti, G. Iacono and A. Guarino, "Early Administration of GOS/FOS Prevents Intestinal and Respiratory Infections in Infants," Journal of Pediatric Gastroenterology and Nutrition, Vol. 42, No. 5, 2006, pp. 2-18.

[93] A. M. Bakker-Zierikzee, E. A. Tol, H. Kroes, M. S. Alles, F. J. Kok and J. G. Bindels, "Faecal SIgA Secretion in Infants Fed on Pre- or Probiotic Infant Formula," Pediatric Allergy and Immunology, Vol. 17, No. 2, 2006, pp. 134-140. doi:10.1111/j.1399-3038.2005.00370.x

[94] G. Veereman, "Pediatric Applications of Inulin and Oligofructose," Journal of Nutrition, Vol. 137, No. 11, 2007, pp. $2585 \mathrm{~S}-2589 \mathrm{~S}$

[95] E. A. Westerbeek, R. M. Van Elburg, A. Van den Berg, J. Van den Berg, J. W. R. Twisk, W. P. Fetter and H. N. Lafeber, "Design of a Randomized Controlled Trial on Immune Effects of Acidic and Neutral Oligosaccharides in the Nutrition of Preterm Infants: Carrot Study," BMC Pediatric, Vol. 8, No. 46, 2008, pp. 1-6.

[96] E. F. Santos, "Effects of Supplementation of the Galactooligosaccharides and Polydextrose on the Calcium and Iron Absorption in Gastrectomized Rats," Master science dissertation, University of Campinas, Campinas, 2007.

[97] A. Drakoularacou, G. Tzortzis, R. A. Rastall and G. R. Gibson, "A Double-blind, Placebocontrolled, Randomized Human Study Assessing the Capacity of a Novel Galactooligosaccharide Mixture in Reducing Travellers' Diarrhoea," European Journal of Clinical Nutrition, Vol. 64, No. 2, 2010, pp. 146-152.

[98] K. J. Jeong, I. Y. Park, M. S. Kim and S. C. Kim, "High-level Expression of an Endoxylanase Gene from Bacillus sp. in Bacillus Subtilis DB104 for the Production of Xylobiose from Xylan," Applied Microbiology and Biotechnology, Vol. 50, No. 1, 1998, pp.113-118.

[99] R. G. Gibson, "Prebiotics," Best Practice and Research Clinical Gastroenterology, Vol. 18, No. 2, 2004, pp. 
287-298.

[100] Y. Suwa, K. Koga, S. Fujikawa, M. Okazaki, T. Irie and T. Nakada, "Bifidobacterium Bifidum Proliferation Promotion Composition Containing Xylooligosaccharide," USA Patent US 5939309, 1999.

[101] J. M. Campbell, G. C. Fahey Jr. and B. W. Wolf, "Selected Indigestible Oligosaccharides Affect Large Bowel Mass, Cecal and Fecal Short-Chain Fatty Acids, $\mathrm{pH}$ and Microflora in Rats," The Journal of Nutrition, Vol. 127, No. 1, 1997, pp. 130-136.

[102] K. Imaizumi, Y. Nakatsu, M. Sato, Y. Sedarnawati and M. Sugano, "Effects of Xylooligosaccharides on Blood Scan," USA Patent US 5939309, 1991. Internet Available: http://www.freepatentsonline.com/5939309.html

[103] M. Okazaki, H. Koda, R. Izumi, S. Fujikawa and N. Matsumoto, "Effect of Xylooligosaccharide on Growth of Intestinal Bacteria and Putrefaction Products," Journal of Japanese Society of Nutrition and Food Science, Vol. 44, No. 1, 1991, pp. 41-44.

[104] G. J. Joo, I. K. Rhee, S. O. Kim and S. J. Rhee, "Effect of Dietary Xylooligosaccharide on Indigestion and Retarding Effect of Bile Acid Movement across a Dialysis Membrane," Journal of the Korean Society of Food Science and Nutrition, Vol. 27, No. 4, 1998, pp. 705-711.

[105] J. Jaskari, P. Kontula, A. Siitonen, H. Jousimies-Somer, T. Mattilasandholm and K. Poutanen, "Oat b-glucan and Xylan Hydrolysates as Selective Substrates for Bifidobacterium and Lactobacillus Strains," Applied Microbiology and Biotechnology, Vol. 49, No. 2, 1998, pp. 175-181. doi:10.1007/s002530051155
[106] C. E. Rycroft, M. R. Jones, G. R. Gibson and R. A. Rastall, "A Comparative In Vitro Evaluation of the Fermentation Properties of Prebiotic Oligosaccharides," Journal of Applied Microbiology, Vol. 91, No. 5, 2001, pp. 878-887. doi:10.1046/j.1365-2672.2001.01446.x

[107] Y. Chung, C. Hsu, C. Ko and Y. Chan, "Dietary Intake of Xylooligosaccharides Improves the Intestinal Microbiota, Fecal Moisture, and pH Value in the Elderly," Nutrition Research, Vol. 27, No. 12, 2007, pp. 756-761. doi:10.1016/j.nutres.2007.09.014

[108] H. Makelainen, S. Forssten, M. Saarinen, J. Stowell, N. Rautonen and A. C. Ouwehand. "Xylo-oligosaccharides Enhance the Growth of Bifidobacteria and Bifidobacterium Lactis in a Simulated Colon Model," Beneficial Microbes, Vol. 1, No. 1, 2010, pp. 81-91. doi:10.3920/BM2009.0025

[109] K. D. Arunachalam, "Role of Bifidobacteria in Nutrition, Medicine and Technology," Nutrition Research, Vol. 19, No. 10, 1999, pp. 1559-1597. doi:10.1016/S0271-5317(99)00112-8

[110] A. Bezkorovainy, "Probiotics: Determinants of Survival and Growth in the Gut," American Journal of Clinical Nutrition, Vol. 73, No. 2, 2001, pp. 399S-405S.

[111] K. E. Scholz-Ahrens, G. Schaafsma, E. G. H. M. Van den Heuvel and J. Schrezenmeir, "Effects of Prebiotics on Mineral Metabolism," American Journal of Clinical Nutrition, Vol. 73, No. 2, 2001, pp. 459S-464S.

[112] F. Gouveia, "Food Industry: The Path of Innovation and New Products," Vol. 2, No. 5, 2006, pp. 32-37. 